\title{
Is the level of eye-hand coordination and executive functioning related to performance in para table tennis players? - An explorative study
}

Irene R. Faber ${ }^{1,2 *}$, Johan Pion ${ }^{3,4}$, Bas Willemse3 ${ }^{3}$, Willianne Schipper³, Maria Nijhuis-Van der Sanden 5

Institute of Sport Science, University of Oldenburg, Oldenburg, Germany; IInternational Table Tennis Federation, Lausanne, Switzerland; 3nstitute for Studies in

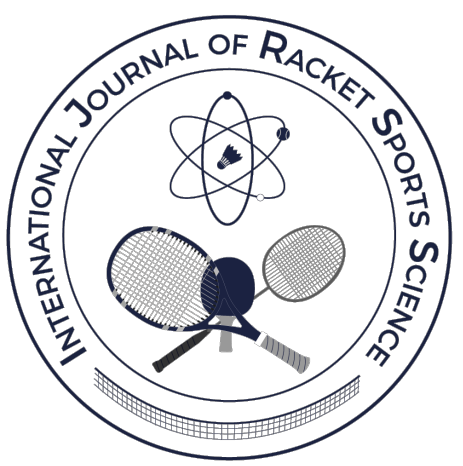
Sports and Exercise, HAN University of Applied Sciences, Nijmegen, The Netherlands; 4Faculty of Medicine and Health Sciences, Department of Movement and Sports Sciences, Ghent University, Ghent, Belgium; ${ }^{5}$ Radboud University Medical Centre, Radboud Institute for Health Sciences, IQhealthcare, Nijmegen, The Netherlands E-mail: irene.faber@uni-oldenburg.de

\begin{abstract}
The goal of this explorative study was to explore whether eye-hand coordination and executive functions (i.e. cognitive flexibility, attention control and information processing) are related to the performance level in para table tennis players. The data of 11 elite (age 15-54) and 11 non-elite para table tennis players (age 13-49) were analyzed. The results showed that the elite players performed better than the median norm values for cognitive flexibility and attention control while the non-elite players demonstrated slower information processing than the median norm values $(\mathrm{p}<0.05)$. The players' competition rating correlated significantly with the eye-hand coordination, cognitive flexibility and information processing measures $(\mathrm{p}<0.05)$. Players with a competition rating $>1000$ points scored $\geq 24$ catches per $30 \mathrm{~s}$ in the eye hand coordination task, whereas the players with < 1000 rating points score $\leq 18$ catches per $30 \mathrm{~s}$. In contrast, there was a clear overlap of scores between the players with $>1000$ and $<1000$ rating scores in the executive functions tests. The results present a first profile of para table tennis players regarding their eye-hand coordination and executive functions and the relationship of these constructs with the performance level. Long-term international cooperation is recommended to understand the value of the measured constructs to predict future successes.
\end{abstract}

Keywords: Sports for Persons with Disabilities, Psychomotor performance, Mental Processes, Aptitude

Cite this article as:

Faber, I., Pion, J., Willemse, B., Schipper, W. \& Nijhuis-Van der Sanden, M. (2019). Is the level of eye-hand coordination and executive functioning related to performance in para table tennis players? - An explorative study. International Journal of Racket Sports Science, 1(1), 45-60. 


\section{Introduction}

The 2016 Paralympic games in Rio de Janeiro hosted 29 medal events for individuals and teams in para table tennis. This relatively high number of medals to distribute is mainly due to the diversity of the players' impairments; para table tennis includes eleven different sport classes (Table 1) (International Table Tennis Federation, 2018). Players that compete while sitting participate in classes 1 to 5 , those who are able to participate standing play in classes 6 to 10. Players with an intellectual impairment participate in class 11. The para table tennis player's classification is allocated through an evaluation before competition by a group of classifiers who are trained and certified by the International Table Tennis Federation. This evaluation may include but is not limited to physical, technical and observation assessments both off - and on- table. More awareness to the Paralympic performance from the spectrum of recreational sport participation to elite level (Blauwet \& Willick, 2012) in combination with the many classes to win a medal in para table tennis, resulted in more attention for para talent programs from national table tennis associations.

The national associations are aiming to find high potential para players and support them with training facilities and personal coaching to improve their success rate. It is a challenge to reveal the determinants that predict future elite performance in para table tennis players, as it is for able bodied table tennis players, since many factors play a role (ElferinkGemser, Jordet, Coelho E Silva, \& Visscher, 2011; Faber, 2016; Gagné, 2004). Similar to the talent identification challenges encountered for typical developing players, one is searching for the performance characteristics that are needed to excel. As para table tennis deals with a relatively small and heterogeneous population of players with a large variety of impairments due to e.g. neurologic, systematic or traumatic conditions, the exploration of these performance characteristics is not easy. Still, it seems worth searching for the key-factors of success to identify players with high potential and connect them to the opportunities for developing their talent.
Table tennis is recognized as one of the fastest sports in the world in terms of game-speed (Abernethy, 1991; Lees, 2003). Although no scientific evidence was found, and this may vary between classifications, it seems likely that elite para table tennis players generally do not reach the same game-speed as in typical table tennis play at the elite level, and rally lengths might also be different and even vary between classes (Fuchs, Faber, \& Lames, 2019). Nevertheless, elite para table tennis players still need to perform a combination of mainly open complex motor skills and tasks under constantly changing conditions with a similar physiological load as in typical table tennis players regardless of their classification (Kondrič, Zagatto, \& Sekulić, 2013; Schmidt \& Lee, 2011). It is likely that the disabilities in para table tennis players will hinder the execution of the intended movements and reaction times to a certain extent while influencing the player's tactical strategies (Kannekens, ElferinkGemser, \& Visscher, 2011; Munivrana, Furjan-Mandić, \& Kondrič, 2015). Consequently, the time frame to respond in para table tennis is still considered relatively short which appeals to a player's processes responsible for purposeful, goal-directed behavior. To explore the parameters that might be associated with high or low performance, it is hypothesized that in each of the para table tennis classes the success of a player is related, at least to a certain extent, to his or her perceptuo-motor and executive functioning capacities.

Recent studies in typically developing table tennis players have produced some interesting results regarding the importance of perceptuo-motor skills for performance. It was found in a prospective study that perceptuo-motor tests assessing ball control could predict future performance in youth table tennis players (R2 $=51 \%, \mathrm{p}<0.001$ ) (Faber, ElferinkGemser, Faber, Oosterveld, \& Nijhuis-Van der Sanden, 2016). These tests focused on the assessment of eyehand coordination while handling a ball (e.g. aiming, dribbling, throwing and catching). This perceptuomotor ability also appears to discriminate between high and low potential youth players (Faber, Oosterveld, \& Nijhuis-Van der Sanden, 2014). These results are in line with the outcomes of other studies in table tennis and tennis demonstrating that eye-hand 
coordination is essential ability for high performance in racket sports (Mantis, Zachopoulou, \& Mavridis, 1998; Nikolić, Furjan-Mandić, Kondrič, 2014; Filipčič \& Filipčič, 2005; Filipčič, Pisk, \& Filipčič, 2010). Regarding para table tennis as a complex motor task, it has many similarities to the challenges in table tennis for typical developing players. In all classifications, most players use their hand to hold the bat and hit the (upcoming) ball under various conditions (e.g. rotation of the ball and speed). Only for some small number of players that use other parts of the body, for example their mouth, to hold the bat this may not be the case. Thus, the level of eye-hand coordination function might be associated with performance in para table tennis players.

A player's level of executive functioning is also likely to be related to table tennis performance. This applies to the regular game of table tennis as well as para table tennis as players need to perform under severe time constraints in changing and unpredictable situations which require a higher level of executive functions in order to be successful (Raab, Masters, \& Maxwell, 2005; Walsh, 2014). Executive functions enable goaldirected, future-oriented behavior (Alvarez \& Emory, 2006) as they are essential for the synthesis of external stimuli, formation of goals and strategies, preparation for action, and verification that plans and actions have been implemented appropriately (Diamond, 2006; Miyake et al., 2000). These are all ingredients of the task 'table tennis' in every match and is considered independent of the classification within para table tennis.

Specifically, the player's cognitive flexibility, attention control and information processing are suggested to be directly related to (para) table tennis performances (Abernethy, 1991; Ak \& Koçak, 2010; Anderson, 2002; Hung, Spalding, Santa Maria, \& Hatfield, 2004; Wang, Guo, \& Zhou, 2016). Cognitive flexibility reflects a player's capacity to adapt quickly to the continuously changing situations (e.g. variations in rotation and speed of the upcoming ball) during a game by initiating creative alternative solutions while learning from mistakes (creativity, working memory and cognitive shifting) (Monsell, 1996). Attention control allows a player to concentrate on each forthcoming rally (selective attention) and to suppress ongoing or planned but inappropriate actions in a given situation (inhibition) (Logan, 1994). The latter might happen when an unexpected service or return (e.g. variation of spin or location) is played by the opponent or the ball hits the net which influences the flight of the ball. A higher level of information processing refers to the ability to generate fast reaction times and psychomotor responses (fluency), which is suggested to accompany better performance in (para) table tennis (Hughes, Bhundell, \& Waken, 1993). Cognitive flexibility and attention control are also termed the 'higher-level' cognitive functions and are involved in the control and regulation of the 'lower-level' cognitive functions e.g. information processing (Diamond, 2006; Sanchez-Cubillo et al., 2009). Considering the task constraints within the game of para table tennis, it seems logical that executive functions are even more important for performance because para players need to deal with personal constraints reducing the number of potential strategies. The connection between executive functions and performance in para table tennis is supported by studies in typical table tennis and other open complex ball sport that confirm the relationship between the level of executive functioning and performance (Huijgen et al., 2015; Verburgh, Scherder, van Lange, \& Oosterlaan, 2014; Vestberg T, Gustafson, Maurex, Ingvar, \& Petrovic, 2012; Wang et al., 2013; Wang, Guo, \& Zhou, 2016). These studies showed that elite (youth) players outperformed their sub-elite or non-elite peers regarding cognitive flexibility and attention control. Though, at this moment there are, to the best of our knowledge, no studies evaluating the executive functions in para table tennis players (classification 1-10).

The present study aimed to explore the relationship between eye-hand coordination and executive functions and the level of table tennis performance in para table tennis players (classification 1-10). Although it was clear that we needed to deal with a rather small and heterogeneous population in para table tennis including different classifications, the approach of this first study concerning provides a model for gaining insights into the factors that determine performance in para table tennis. For this 
purpose, the level of eye-hand coordination and executive functioning of para table tennis players was first individually profiled and compared to the norm population (when available) while taking age and sex into account. Second, the association between the level of eye-hand coordination and executive functioning and the players' table tennis performance was explored.

\section{Methods}

\section{Study design}

A cross-sectional study design was used to explore the eye-hand coordination and the executive functions in para table tennis players. The study protocol and informed consent procedure were approved by the Ethics Committee of the Medical Spectrum Twente (Medical School Twente, Institute for Applied Science, Enschede, the Netherlands; METC/13053.fab 19-22013) in full compliance with the Declaration of Helsinki. Written informed parental consent and player assent were obtained for all players under the age of 18 years. Written informed consent was obtained for all adult players.

\section{Participants}

Para table tennis players from different training/playing levels were recruited with support from the Netherlands Table Tennis Association's coaches of the Paralympic division. Some of the recruited players were from the national para table tennis training group and were proven or expected by expert national coaches to become successful at the international para table tennis level. They were all ranked in the top 2 of their classification category. This subgroup was called the elite group or elites. The other recruited players only trained at their local club and were not expected to be selected for a talent program and/or reach international level. This subgroup was called the non-elite group or non-elites.

The data of 22 para table tennis players including 11 elite players (age 15-54 years; 9 males and 2 females) and 11 non-elite players (age 13-49 years; 8 males and 3 females) were analyzed in this study (Table 1). All players were officially classified into a sport class matching their function level. Four elite players and 7 non-elite players were sitting in a wheelchair when playing table tennis. All the others play table tennis while standing. The underlying causes of the players' impairments were diverse and contained both neurological (e.g. cerebral palsy, spina bifida, spinal cord injury and brain trauma) and orthopedic (e.g. clubfeet, scoliosis, growth deficits) conditions or a combination. The elite and non-elite group contained 3 and 4 players with brain damage (i.e. cerebral palsy or brain trauma), respectively. The elite group showed significantly higher competition rating scores $(\mathrm{p}<$ $0.001)$, training hours per week $(\mathrm{p}<0.003)$ and total training volumes $(\mathrm{p}<0.002)$ than their non-elite peers.

\section{Measurements}

\section{Eye-hand coordination}

Eye-hand coordination was assessed using the eyehand coordination test item of the Dutch perceptuomotor skills assessment (Faber et al., 2016; Faber et al., 2014). The standardization of the test is captured in a protocol (Faber et al., 2016). During the eye-hand coordination test players need to throw a ball at a vertically positioned table tennis table at 1-meter distance with one hand and to catch the ball correctly with the other hand as many times as possible in $30 \mathrm{~s}$. A modification on the original protocol was introduced for the players who lacked function of upper extremity of one side of the body to catch the ball as a consequence of his / her disability (e.g. unilateral spastic paralysis due to cerebral palsy). In these cases, players were allowed to use one hand to throw and catch the ball. The best number of correct catches from two attempts was recorded as raw outcome score. Since no norm values are available, it was not possible to convert the raw scores into scaled or percentile scores. The reproducibility of the eye-hand coordination test is considered satisfactory (ICC 0.91; 95\% confidence interval 0.85-0.95; $\mathrm{p}<0.001$ ); CV 7\%) (Faber, Nijhuis-Van Der Sanden, Elferink-Gemser, \& Oosterveld, 2015). 
Table 1.

Characteristics of the included para table tennis players

\begin{tabular}{|c|c|c|c|c|}
\hline & & Total & Elite & Non-elite \\
\hline $\mathrm{N}$ & & 22 & 11 & 11 \\
\hline Age (years) & & $27(13-54)$ & $23(15-54)$ & $39(13-49)$ \\
\hline \multirow[t]{2}{*}{$\operatorname{Sex}(n)$} & Male & 17 & 9 & 8 \\
\hline & Female & 5 & 2 & 3 \\
\hline Brain damage (n) & & 7 & 3 & 4 \\
\hline \multirow[t]{12}{*}{ Classification (n) } & Wheel-chair bounded & 11 & 4 & 7 \\
\hline & 1 & 1 & - & 1 \\
\hline & 2 & 3 & 2 & 1 \\
\hline & 3 & 1 & - & 1 \\
\hline & 4 & - & - & - \\
\hline & 5 & 6 & 2 & 4 \\
\hline & Standing & 11 & 7 & 4 \\
\hline & 6 & - & - & - \\
\hline & 7 & 3 & 3 & - \\
\hline & 8 & 3 & 2 & 1 \\
\hline & 9 & 2 & 1 & 1 \\
\hline & 10 & 3 & 1 & 2 \\
\hline \multicolumn{2}{|c|}{ Competition rating score (points) $^{*}$} & $705(0-2252)$ & $1317(636-2252)$ & $472(0-1006)$ \\
\hline \multicolumn{2}{|c|}{ Training (hours/week) ${ }^{*}$} & $10(1-20)$ & $18(6-20)$ & $5.5(1-14)$ \\
\hline \multicolumn{2}{|c|}{ Training volume (hours)* } & $1500(40-7800)$ & $2280(240-7800)$ & $740(40-2200)$ \\
\hline
\end{tabular}

Age, rating, training and training volume are presented in medians and ranges. Other data are frequencies. ${ }^{*} \mathrm{p}<0.01$ showing a significant difference between the elites and non-elites.

\section{Executive functions}

The executive functions of cognitive flexibility (creativity, working memory and cognitive switching), attention control (inhibition) and information processing (psychomotor response) were assessed in all participating players. To cover all constructs a combination of three tests was used: The D-KEFS Design Fluency test, the Trail Making test and the Stroop test. In all tests, raw scores were determined and converted into scaled or percentile scores based on the available norm values that include a correction for age and sex. Validity and reliability are reported to be satisfactory for all executive measures (McLeod, Barr, McCrea, \& Guskiewicz, 2006; Strauss, Sherman, \& Spreen 2006; Swanson, 2005).
The D-KEFS Design Fluency test is a standardized test and measures cognitive flexibility and attention control (Delis, Kaplan, \& Kramer, 2001). The task is administered with pen and paper and consists of three conditions: 1) filled dots, 2) empty dots, and 3) switching. In the first condition, a sheet with squares containing with five filled dots is presented to the participant. The participant is asked to draw as many unique designs as possible in 60 seconds using four straight lines in each square to connect the dots (creativity and working memory). In the second condition the squares contain five filled dots and five empty dots. The participant is instructed to use the empty dots to connect the four lines, and ignore the filled dots (creativity, working memory and inhibition). The third condition consists of squares containing five filled dots and five empty dots as well. 
In this condition, the participant is instructed to alternate between the filled and empty dots when drawing the designs, so that each line is drawn between a filled and an empty dot (creativity, working memory and cognitive switching). For each condition the total number of correct, unique designs was determined and used as raw score. The higher number of designs, the better a player's executive functions. The raw scores of each condition were converted into scaled scores based on the manual's norm values (Delis et al., 2001). A scaled value of 10 represents the $50^{\text {th }}$ percentile score with 3 points counting as one standard deviation. The sum of the scaled scored of all three conditions was calculated as a total score, which was also converted into a scaled score. To obtain a more specific score for the players' cognitive switching ability a contrast score was calculated by subtracting the combined scaled score of condition 1 and 2 from the scaled score of condition 3. This contrast score was again scaled based on the norm values.

The Trail Making test is a paper-and-pencil task that measures cognitive flexibility and information processing and has two conditions: 1.) Trail A, a number-sequencing task and 2.) Trail $\mathrm{B}$, a numberletter switching task (Reitan, Kaplan, \& Kramer, 1971). Trail A consists of encircled subsequent numbers from 1 to 25 placed on a paper. Participants are asked to connect the dots in numerical order as quickly as possible by drawing a line from one dot to the next (psychomotor response). Trail B consists of encircled numbers (1 to 13) and encircled letters (A to L). In this condition, participants need to connect the dots as quickly as possible while alternating between a numerical and an alphabetical order (i.e. 1-A-2-B-3-C4-D-5-E and so on) (cognitive flexibility). Timedurations in both conditions were measured in seconds and used as raw scores and converted into percentile scores (Tombaugh, 2004). Faster times reflect a higher level of information processing (Trail A) and cognitive flexibility (Trail B). A contrast score was again calculated for better estimating the player's cognitive switching ability by subtracting the raw scores of Trail A from the raw score of Trail B (Strauss et al., 2006; Eggermont, Milberg, Lipsitz, Scherder, Leveille, 2009).
Golden's Stroop test was used to measure attention control and information processing (Golden, 1975). Participants need to complete three different reading conditions. In each condition, a different reading card is presented: 1.) a card with 100 color words (i.e. 'green', 'yellow', 'red', and 'blue') (psychomotor response), 2.) a card with 100 solid colored rectangles (psychomotor response), and 3.) a card with 100 color words printed in colored ink, yet not the ink of the word itself, in the third condition (inhibition). Participants are asked to read as many colors aloud as possible in 45 seconds in all three conditions. In the third condition the participants need to suppress an automatic response as they were asked to name the color of the ink, instead of reading the word. The numbers of correct responses of each condition were used as raw scores and converted into scaled scores (Rognoni et al., 2013). A scaled value of 10 represents the $50^{\text {th }}$ percentile score with 3 points counting as one standard deviation. The error rates per condition were also noted. The number of correct responses in the third condition, divided by the number of correct responses in the second condition, resulted in the Stroop-ratio. This ratio reflects a player's level of inhibition, independently of his / her ability to name colors while avoiding an emphasis on reading ability (Homack \& Riccio, 2004; Lansbergen, Kenemans, \& van Engeland, 2007). A higher Stroop-ratio indicates better inhibitory control.

\section{Table tennis performance}

Competition rating scores indicating the player's individual competition performance at the moment of testing were obtained for each player from the Netherlands Table Tennis Association's archives. The higher the rating score the better the player's table tennis performance. The competition rating score compares performances between players (youth and adult players, male and female players) who participate in any of the regional and national competition leagues and does not take into account the classification of the player for para table tennis (Faber et al., 2016). Besides the competition rating score, the classification, the current training hours per week and the total training volume (i.e. accumulation of the training hours per 
week multiplied by 40 weeks per training year) were acquired by using a short questionnaire to characterize the included players.

\section{Data collection}

All data were collected between February to June 2016. All players were under similar conditions after a regular training at their training center. None of the players had previous experience with the eye hand coordination test and executive function tests. The eyehand coordination test was administered first, followed by the D-KEFS Design Fluency test, the Trail Making test and the Stroop test. All measurements were conducted by the same assessor who familiarized herself with the test-protocols and instruction and feedback was given during a training by an expert. The test session lasted for approximately $30 \mathrm{~min}$ for each player. The short questionnaire for table tennis parameters was filled in just before or just after the test session.

\section{Statistical analysis}

IBM SPSS Statistics 23 (IBM Corp., Armonk, New York, United States of America) was used for the statistical analyses. Sample characteristics were presented for the total groups and the subgroups (i.e. elites and non-elites). A Mann-Whitney $U$ test was used to test for differences between the elites and nonelites regarding the sample characteristics competition rating score, the current training hours per week and the total training volume. Spider diagrams were used per classification to demonstrate the players' individual profiles. One-sample Wilcoxon-Signed Rank tests were used to test if the elite and non-elite players scored significantly better or lower than the norm population on the executive function tests. For this purpose, the scaled scores based on the norm values, correcting for age and sex, were used and compared to the median value of the norm population (D-KEFS Design Fluency test 10; Trail Making test 50; Stroop test 10). No comparison could be made to the norm population for the eye-hand coordination test, since no norm values were available in the age-span of the participants for this test. The associations between all test outcomes (i.e. the raw, the scaled / percentile, the contrast as well as the ratio scores) and the table performance outcome (i.e. competition rating score) were firstly evaluated by calculating Spearman's correlation coefficients and partial correlation coefficient with training volume as a controlling variable. Hinkle's rule of thumb was used for the interpretation of the correlation coefficients' sizes (Hinkle, Wiersma, \& Jurs, 2003). Secondly, scatter plots were used to explore the players' profiles regarding the level of eyehand coordination and executive functioning and the level of performance. Only the total score of the DKEFS Design Fluency test and the outcomes of Trail B of the Trail Making test and color-word condition of the Stroop test were included for this exploration to reflect the executive functioning. Alpha was set at 0.05 for significance for the inferential analyses; the alpha was not adjusted (i.e. lowered) for the multiple testing because of the explorative character of this pilot study. This is supported by Hopkins (2000) stating that the cut-off of $5 \%$ can be too stringent for a decision limit in athletes.

\section{Results}

Figure 1 summarizes the raw test scores for each individual player per classification combined with other player characteristics (e.g. sex, age, training volume). The figure holds no diagram for the classification 4 and 6 as no players were included belonging to these sports classes. The rank position shown in figure 1 is the ranking position within the included sample and is based on the competition rating scores. The elite players covered ranking 1 to $8,10,13$ and 14 , the non-elites $9,11,12$ and 15 to 18 . There were five players that had no rating points, which caused the same ranking (Figure 1.d \#18). Four players (Figure 1: \#3, \#6, \#9 and \#12) had difficulties in catching the ball with both the left and right hand alternately during the eye-hand coordination test. For that reason, they performed the test while only using one hand. Based on the individual profiles in Figure 1, it appears that the elite players tend to catch more balls (eye-hand coordination), to make more unique designs under time pressure and to be faster in making a correct trail (cognitive flexibility), reading words and colours (psychomotor responses) than the non-elites. 
No trends were recognized in the exploring subgroup analyses for the players suffering from brain damage.

Table 2 presents the outcomes of the eye-hand coordination and executive function assessment of the elite and non-elite players. There was only one missing value at the Trail Making test, because one player gave up after $180 \mathrm{~s}$. The one-sample Wilcoxon-Signed Rank tests revealed that the elite players scored significantly higher than the median norm values at condition 1 (creativity and working memory) $(p=0.016)$ and 3 (creativity, working memory and switching ability) ( $p$ $=0.033)$ and at the scaled score of the total of the scaled scores (cognitive flexibility) $(p=0.022)$ of the D-KEFS Design Fluency test. Still, no significant better scores were found for the Design Fluency test's scaled contrast score reflecting specifically the cognitive switching ability $(p=0.180)$. The Trail Making test did not reveal any significant differences from the norm median for the elites, but the non-elites performed significantly lower than the $50^{\text {th }}$ percentile on Trail A (psychomotor response) $(p=0.007)$ and Trail B (cognitive flexibility) $(p=0.002)$. The non-elites also showed a significantly lower score on the Stroop test than the norm median for the word reading condition (psychomotor response) $(p=0.011)$. This was not revealed for the other two conditions. In contrast, the elite players performed significantly better at the colour-word condition than the median norm value

(inhibition) $(p=0.016)$. Only a small number of errors were made in the Stroop test conditions (Figure 1). Nine elites and 7 non-elites showed no errors during the test. Of the remaining players 4 (1 elite and 3 non-elite) had errors (1-3) at the colour-condition and 2 ( 1 elite and 1 non-elite) had errors (4) at the colour-word condition.

Table 3 shows the evaluation of the associations between the test results and the performance outcome. The eye-hand coordination test showed a significant high positive correlation with the competition rating scores $(\mathrm{R}=0.86, p<0.001)$ indicating that the better performers of the test are also the better para table tennis players in the regular competition that does not take into account the player's para table tennis classification. Also when controlling for training volume the correlation coefficient remained significant high $(\rho=0.79, p<0.001)$. Furthermore, significant low to moderate Spearman correlation coefficients were found between the D-KEFS Design Fluency test outcomes and the competition rating scores ( $\mathrm{R}$ ranging from 0.49-0.58) and also between the Trail Making test and the competition rating scores $(\mathrm{R}=-0.71$ (Trail A) and -0.46 (Trail B)). The better players tended to perform better on the cognitive flexibility tests. Only the contrast scores of these tests referring to the cognitive switching ability did not reveal any significant association with the table tennis performance outcome. Most of the significant correlations remained moderate when using training volume as a control variable at the D-KEFS conditions; for conditions 2 and 3 and for the total of scaled scores the partial correlations were between 0.46 to 0.57 ( $p<$ 0.05). The correlation coefficients in the Trail Making test were somewhat reduced when controlling for training volume in Trail A (raw score $\rho=-0.56, p=$ 0.010 ; scaled score $\rho=0.49, p=0.028$ ) but slightly increased in Trail B (raw score $\rho=-0.53, p=0.016$ ). Regarding the Stroop test only the colour condition (psychomotor response) showed a significant moderate positive correlation ( $\mathrm{R}=0.424, p=0.049)$. This correlation became insignificant when controlling for training volume.

Finally, the relations between the level of eye-hand coordination and executive functioning and the level of performance are presented in Figure 2 by means of three scatter plots. No clear trends (e.g. linear or polynomial) could be detected from Figure 2 about the interrelationships of the test outcomes (i.e. eye hand coordination test and executive function tests) and performance. However, as presented in Table 1, a higher rating seems to be accompanied by a higher level of eye hand performance whereas this trend is less clear for the executive function outcomes. Players with a competition rating $>1000$ points scored $\geq 24$ catches/30 seconds in the eye hand coordination task, whereas the players with $<1000$ rating points score $\leq$ 18 catches/30 seconds. In contrast, there was an clear overlap of scores between the players $>1000$ and $<1000$ rating scores in the executive functions tests (Figure 2). 

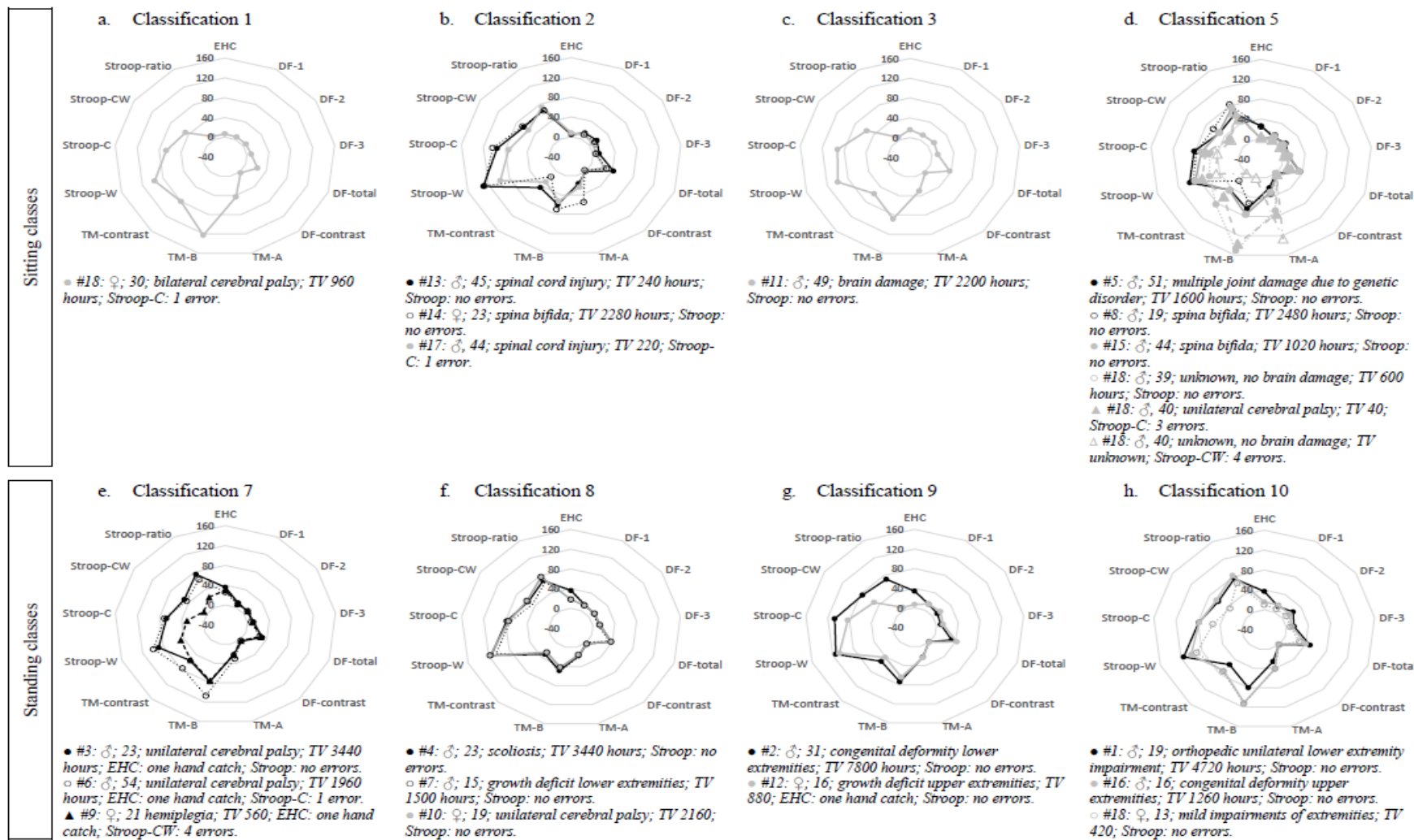

Figure 1. Individual profiles of the included players per classification.

Data represent the raw scores per test condition. The results in black refer to the elite players and in grey to the non-elite players. The Stroop-ratio was presented as a percentage. EHC = eye-hand coordination test; DF = D-KEFS Design Fluency test; TM = Trail Making test, Stroop-W = word condition, Stroop-C = colour condition, Stroop-CW = colour-word condition; $\mathrm{TV}=$ training volume.

Table 2.

Eye-hand coordination and executive functions in para table tennis players

\begin{tabular}{|c|c|c|c|c|c|c|c|}
\hline & & \multicolumn{3}{|c|}{$\begin{array}{c}\text { Elite } \\
(\mathrm{n}=11)\end{array}$} & \multicolumn{3}{|c|}{$\begin{array}{c}\text { Non-elite } \\
(\mathrm{n}=11)\end{array}$} \\
\hline & & raw & scaled & $p$-value & raw & scaled & $p$-value \\
\hline \multicolumn{2}{|c|}{ Eye-hand coordination (catches/30s)^ } & $26(4-38)$ & - & - & $7(0-30)$ & - & - \\
\hline \multirow{5}{*}{$\begin{array}{l}\text { D-KEFS } \\
\text { Design } \\
\text { Fluency test }\end{array}$} & condition 1 & $13(7-14)$ & $13(8-13)^{1}$ & $0.016^{*}$ & $9(3-16)$ & $9(4-15)$ & 0.257 \\
\hline & condition 2 & $10(7-23)$ & $9(7-19)$ & 0.766 & $9(1-17)$ & $9(2-15)$ & 0.326 \\
\hline & condition 3 & $10(5-14)$ & $12(7-16)^{1}$ & $0.033^{*}$ & $8(2-12)$ & $10(4-14)$ & 0.952 \\
\hline & total of scaled scores & $34(24-48)$ & $12(8-18)^{1}$ & $0.022^{*}$ & $28(11-42)$ & $10(3-15)$ & 0.622 \\
\hline & contrast score $(3-(1+2))$ & $0(-2-4)$ & $10(8-14)$ & 0.180 & $2(-3-4)$ & $12(7-14)$ & 0.165 \\
\hline \multirow{3}{*}{$\begin{array}{l}\text { Trail Making } \\
\text { test }\end{array}$} & Trail A & $22(16-33)$ & $60(10-90)$ & 0.235 & $41(22-126)$ & $10(10-60)^{2}$ & $0.007^{* *}$ \\
\hline & Trail B & $60(42-107)$ & $40(10-70)$ & 0.088 & $99.5(64-151)^{\#}$ & $10(10-20)^{2}$ & $0.002^{* *}$ \\
\hline & contrast score $(B-A)^{\wedge}$ & $44(20-77)$ & $-\wedge$ & & $60(15-83)^{\#}$ & - & - \\
\hline
\end{tabular}




\begin{tabular}{rrcccccc}
\hline Stroop test & word & $106(89-130)$ & $9(5-14)$ & 0.181 & $90(46-128)$ & $5(2-14)^{2}$ & $0.011^{*}$ \\
color & $78(67-107)$ & $10(8-18)$ & 0.491 & $67(30-103)$ & $8(2-17)$ & 0.153 \\
color-word & $54(45-76)$ & $12(9-17)^{1}$ & $0.016^{*}$ & $47(7-67)$ & $10(2-15)$ & 0.310 \\
& ratio (color-word/color) & & $0.71(0.62-0.83)$ & - & & $0.65(0.23-0.83)$ & - \\
\hline
\end{tabular}

Data are presented in medians and ranges. ${ }^{\wedge}$ Norm values not available. ${ }^{*} p<0.05,{ }^{* *} p<0.05$ : showing a significant difference with the norm values. ${ }^{*}$ One missing; the player gave up after $180 \mathrm{~s}$. ${ }^{1}$ elite players scored significantly better than the median norm value (D-KEFS Design Fluency test 10; Stroop test 10) $(p<0.05)$. ${ }^{2}$ non-elite players scored significantly lower than the median norm value (Trail Making test 50; Stroop test 10) $(p<0.05)$.

Table 3.

Association between eye-hand coordination and executive functions assessments outcomes and table tennis performance in para table tennis players $(n=22)$

\begin{tabular}{|c|c|c|c|c|c|c|c|c|c|}
\hline & & \multicolumn{4}{|c|}{$\begin{array}{l}\text { Competition rating score } \\
\text { versus the raw scores }\end{array}$} & \multicolumn{4}{|c|}{$\begin{array}{l}\text { Competition rating score } \\
\text { versus the scaled scores }\end{array}$} \\
\hline & & $\mathrm{R}$ & $p$ & $\rho$ & $p$ & $\mathrm{R}$ & $p$ & $\rho$ & $p$ \\
\hline \multicolumn{2}{|c|}{ Eye-hand coordination (catches/30s) } & $0.86^{* *}$ & $<0.001$ & $0.79^{* *}$ & $<0.001$ & - & - & - & - \\
\hline \multirow{5}{*}{$\begin{array}{l}\text { D-KEFS } \\
\text { Design } \\
\text { Fluency } \\
\text { test }\end{array}$} & condition 1 & $0.51^{*}$ & 0.016 & 0.38 & 0.103 & $0.55^{* *}$ & 0.009 & 0.40 & 0.081 \\
\hline & condition 2 & $0.49^{*}$ & 0.022 & $0.48^{*}$ & 0.034 & 0.41 & 0.057 & $0.46^{*}$ & 0.043 \\
\hline & condition 3 & $0.58^{* *}$ & 0.005 & $0.57^{*}$ & 0.009 & $0.56^{* *}$ & 0.007 & $0.56^{*}$ & 0.010 \\
\hline & total of scaled scores & $0.52^{*}$ & 0.012 & $0.52^{*}$ & 0.019 & $0.51^{*}$ & 0.016 & $0.52^{*}$ & 0.019 \\
\hline & contrast score $(3-(1+2))$ & 0.04 & 0.863 & 0.16 & 0.509 & 0.04 & 0.863 & 0.16 & 0.509 \\
\hline \multirow{3}{*}{$\begin{array}{l}\text { Trail } \\
\text { Making } \\
\text { test }\end{array}$} & Trail A & $-0.71^{* *}$ & $<0.001$ & $-0.56^{*}$ & 0.010 & $0.66^{* *}$ & $<0.001$ & $0.49^{*}$ & 0.028 \\
\hline & Trail B & $-0.46^{*}, *$ & 0.035 & $-0.53^{* * \#}$ & 0.016 & 0.20 & 0.375 & 0.286 & 0.221 \\
\hline & contrast score (B-A) & $-0.30^{\#}$ & 0.191 & -0.36 & 0.118 & - & - & - & - \\
\hline \multirow{4}{*}{$\begin{array}{l}\text { Stroop } \\
\text { test }\end{array}$} & word & 0.39 & 0.073 & 0.11 & 0.645 & 0.41 & 0.056 & 0.21 & 0.373 \\
\hline & color & $0.42^{*}$ & 0.049 & -0.07 & 0.773 & $0.44^{*}$ & 0.040 & -0.02 & 0.929 \\
\hline & color-word & 0.35 & 0.107 & -0.09 & 0.715 & 0.36 & 0.105 & -0.02 & 0.937 \\
\hline & ratio (color-word/color) & 0.23 & 0.307 & -0.14 & 0.550 & - & - & -- & \\
\hline
\end{tabular}

$\mathrm{R}=$ Spearman's correlation coefficients. $\rho$ = partial Spearman's correlation coefficients correcting for training volume. ${ }^{*} p<$ 0.05 and " $p<0.01$ showing a significant difference between the groups. ${ }^{*}$ One missing; the player gave up after $180 \mathrm{~s}$. 
A.

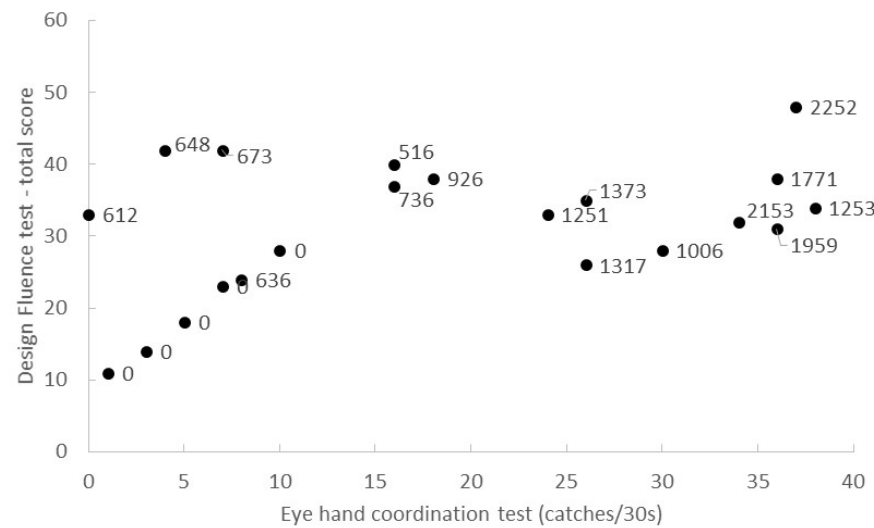

B.

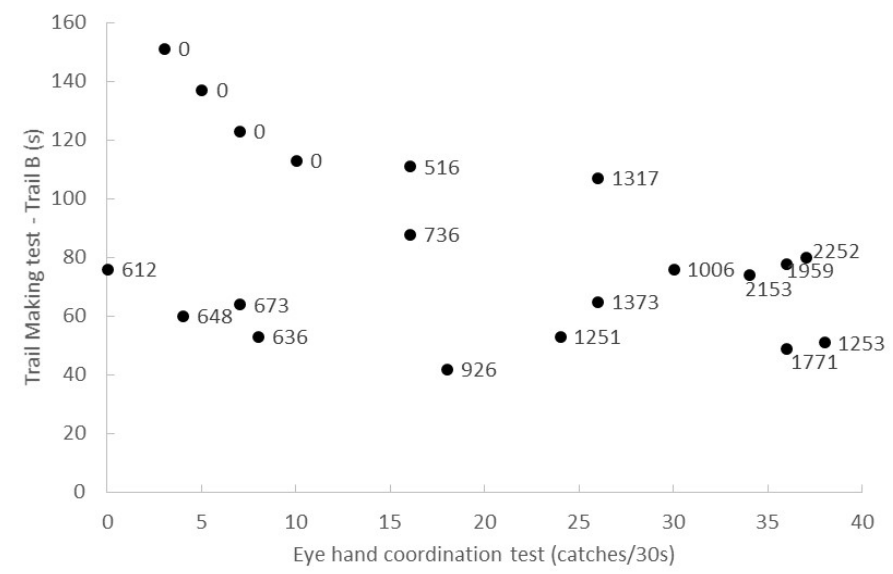

C.

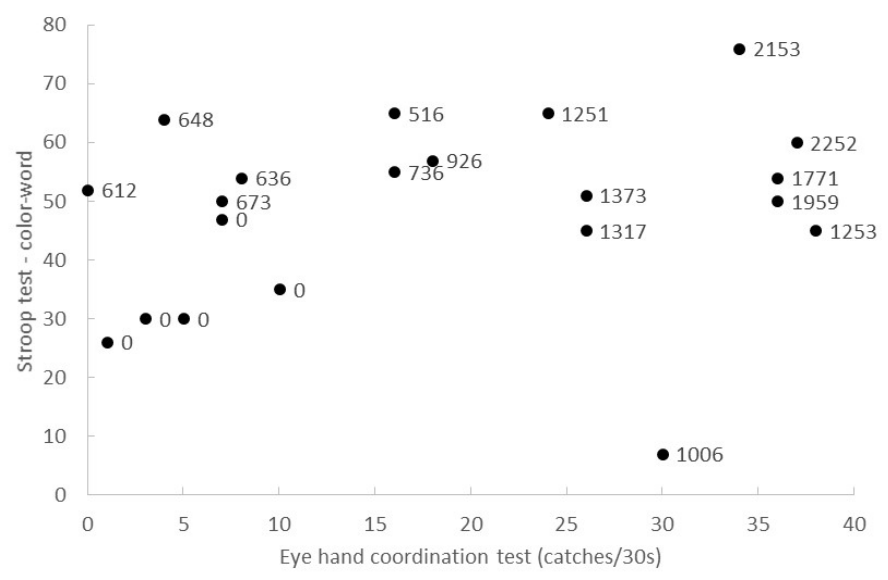

Figure 2. Exploration of the association between the level of eye-hand coordination and executive functioning and the level of performance. 


\section{Discussion}

The results of this pilot-study indicate that, as hypothesized, the current level of table tennis performance in para table tennis players is related to the player's level of eye-hand coordination and the measured executive functions even when there is control for the training volume. The results concerning eye-hand coordination correspond to the findings in typical developing racket sport players (Faber et al., 2014, 2016; Mantis et al., 1998; Nikolić et al., 2014; Filipčič \& Filipčič, 2005; Filipčič et al., 2010; Panjan et al., 2010). Eight of the elite para table tennis players scored within the range (mean $\pm 2 * \mathrm{SD}$ ) presented by the typical developing Dutch elite and sub-elite table tennis players (elite $33 \pm 5$; sub-elite $30 \pm 5$ ) (ElferinkGemser et al., 2018), whereas only one non-elite para table tennis player reached this level. As eye-hand coordination might differ considerably in para table tennis players as a consequence of the various impairments, this might even be more related to the playing level than in typical developing players. Especially in those players where the coordination of the hand function is impaired as a consequence of a neurological condition (e.g. brain damage). On the other hand, it is important to keep in mind that the analysis was conducted on players competing in different playing classes. A within-class analyses is necessary to gain more insight in the association of the eye hand coordination test outcomes and the level of performance. Especially as the game characteristics between classes can vary (Fuchs et al., 2019).

Regarding the executive function results, it seems likely that specifically cognitive flexibility and information processing are related to performance in para table tennis players. The elite players showed better levels of creativity and working memory compared to the norm population (corrected for age and sex) whereas the non-elite players did not, which was associated with a higher performance level in national competition even when controlling for training volume. These findings are in line with the results of previous studies conforming the association between cognitive flexibility and sports performance (Huijgen et al., 2015, Verburgh et al., 2014; Vestberg et al.,2012). Moreover, recently published data in typical developing elite and sub-elite Dutch table tennis players also revealed that these high-level players score significantly better than the norms on creativity and working memory $(p<0.05)$ (ElferinkGemser et al., 2018). In contrast, Huijgen et al. (2015) did not find differences in the lower cognitive functions, i.e. information processing, between elite and sub-elite youth soccer players. Our results showed that the non-elite players' psychomotor responses were slower than those of the norm population and of the elite players and that these were associated with a low competition level. This is possibly best explained by the differences in the included sample and perhaps in the difference of game speed between soccer and table tennis. Yet, it must be acknowledged that although contrast scores were used to better indicate the level of specific cognitive functions, the influence of motor speed on the results has not been evaluated by means of a pure motor speed task. Including an appropriate test for the para table tennis players in future studies measuring this construct (e.g. finger tapping task) might provide new insights. For the executive function tests, it is also important to conduct within class analyses with specific characteristics (Fuchs et al., 2019) to better understand the value for para players competing in the same class.

Although, these interpretations of the results seem logical and supported by other studies, hard conclusions based on our results cannot be drawn. However, this study is intended to serve as a startingpoint and some concessions for feasibility reasons had to be made in the study design and the analyses. First, this study used a cross-sectional design due to timeconstraints, which prevents any conclusion about causality. Although associations were found, it cannot be confirmed whether better performance was a consequence of better eye-hand coordination or executive functioning. Longitudinal studies are needed in the future. Second, no hard conclusion can be drawn about the heredity component (i.e. natural ability) or trainability of eye-hand coordination and the measured executive functions to influence the performance level. A better insight in the influence of training on the outcome variables is needed. Although statistical 
corrections were made for the players' total training volume and it was shown that most associations remained significant which could refer to a natural ability, it must be acknowledged that the design is cross-sectional and the sample of this study is only small. Both prevent us to make conclusions about the direction of the associations that was found. Third, the reproducibility of the eye-hand coordination test has not been studied yet in a sample including para table tennis players and using the modification for players with a unilateral impairment of the upper extremity (i.e. using only one hand). However, since the reproducibility was already confirmed satisfactory in young children (age 6-10) (Faber et al., 2015), we assume that this is generalizable for our sample. Fourth, general tests were used to assess the executive functions. Concerning task-specificity future studies could focus on (the development of) tests that are more closely connected to table tennis. Fifth, the type- 1 error is increased in this study; the alpha was not adjusted for multiple testing as we intended to find first starting points. It is recommended, however, to take the possibility of adjustment of the alpha into account in future studies (Field, 2013). Finally, the small sample size prevented subgroup analyses per age and classification. Such analyses are crucial to better understand what key factors determine performance in a certain age and specific class in para table tennis. An international approach in which data of the nation's samples can be combined and analyzed together is recommended for this purpose.

\section{Conclusions}

In conclusion, this pilot-study intends to serve as a starting-point for searching determinants of performance in para table tennis players. Although there are limitations in this study and no hard conclusion can be drawn, the results present a first profile of para table tennis players regarding their eyehand coordination and executive functions and the relationship of these constructs with the performance level. We call scientists, associations and coaches to start an international cooperation in this field to make it possible to evaluate determinants for performance per classification and per age-group including eye-hand coordination and executive functions. Moreover, we recommend a longitudinal approach in which players will be monitored over time.

\section{Acknowledgments}

We acknowledge the players and trainers of the Netherlands Table Tennis Association for their cooperation in data-collection. Special thanks go to prof. Matthieu Lenoir for his valuable feedback on earlier versions of our paper.

\section{References}

Abernethy, B. (1991). Visual search strategies and decision-making in sport. International Journal of Sport Psychology, 22, 189-210.

Ak, E., \& Koçak, S. (2010). Coincidence-anticipation timing and reaction time in youth tennis and table tennis players. Perceptual and motor skills, 110(3), 879887.

Alvarez, J. A., \& Emory, E. (2006). Executive function and the frontal lobes: a meta-analytic review. Neuropsychology review, 16(1), 17-42.

Anderson, P. (2002). Assessment and development of executive function (EF) during childhood. Child Neuropsychology, 8(2), 71-82.

Blauwet, C., \& Willick, S.E. (2012). The Paralympic Movement: using sports to promote health, disability rights, and social integration for athletes with disabilities. PMER, 4(11), 851-856.

Delis, D. C., Kaplan, E., \& Kramer, J.H. (2001). DelisKaplan executive function system (D-KEFS). Psychological Corporation.

De Vries, S. J., Verwoert, T., Van Otten, S., \& Faber, I. R. (2014). Cognitive functions of elite and sub-elite table tennis players. In L. Jans \& S. Vos (Eds.), Abstractbook of 'Dag van het Sportonderzoek 2013' (p. 126). Eindhoven: Fontys Sporthogeschool.

Diamond, A. (2006). The early development of executive functions. In E. Bialystok \& F.I. Craik (Eds.), Lifespan cognition: Mechanisms of change (pp. 70-95). Oxford: Oxford University Press.

Elferink-Gemser, M., Jordet, G., Coelho E Silva, M.J. \& Visscher, C. (2011). The marvels of elite sports: How 
to get there? British Journal of Sports Medicine, 45, 683684.

Elferink-Gemser, M. T., Faber, I. R., Visscher, C., Hung, T. M., de Vries, S. J., \& Nijhuis-Van der Sanden, M. W. (2018). Higher-level cognitive functions in Dutch elite and sub-elite table tennis players. PloS one, 13(11), e0206151.

Eggermont, L.H.P., Milberg, W.P., Lipsitz, L.A., Scherder, E.J.A., \& Leveille, S.G. (2009). Physical activity and executive function in aging: the MOBILIZE Boston study. Journal of American Geriatric Society, 57(10), 1750-6.

Faber, I.R., Oosterveld, F.G.J., \& Nijhuis-Van der Sanden, M.W.G. (2014). Does an Eye-Hand Coordination Test Have Added Value as Part of Talent Identification in Table Tennis? A Validity and Reproducibility Study. PLoS ONE 9(1): e85657. doi:10.1371/journal.pone.0085657

Faber, I. R., Nijhuis-Van Der Sanden, M. W., Elferink-Gemser, M. T., \& Oosterveld, F. G. (2015). The Dutch motor skills assessment as tool for talent development in table tennis: a reproducibility and validity study. Journal of Sports Sciences, 33(11), 11491158.

Faber, I. R., Elferink-Gemser, M. T., Faber, N. R., Oosterveld, F. G., \& Nijhuis-Van der Sanden, M. W. (2016). Can Perceptuo-Motor Skills Assessment Outcomes in Young Table Tennis Players (7-11 years) Predict Future Competition Participation and Performance? An Observational Prospective Study. PloS one, 11 (2), e0149037.

Faber, I.R. (2016). Diamonds in the rough. Searching for high potential in youth table tennis players. Twello, The Netherlands. doi: 10.13140/RG.2.2.29352.78082.

Field, A. (2013). Discovering statistics using IBM SPSS statistics. London: Sage Publications Ltd.

Filipčič, A., \& Filipčič, T. (2005). The relationship of tennis-specific motor abilities and the competition efficiency of young female tennis players. Kinesiology, 37(2), 164-172.

Filipčič, A., Pisk, L., \& Filipčič, T. (2010). Relationship between the results of selected motor tests and competitive successfulness in tennis for different age categories. Kinesiology, 42(2), 175-183.
Fuchs, M., Faber, I. R., \& Lames, M. (2019). Game characteristics in elite para table tennis. German Journal of Exercise and Sport Research, 49(3), 251-258.

Gagné, F. (2004). Transforming Gifts into talents: the DGMT as a developmental theory 1. High ability studies, 15(2), 119-147.

Golden, C. J. (1975). The measurement of creativity by the Stroop Color and Word Test. Journal of personality assessment, 39(5), 502-506.

Hinkle, D. E., Wiersma, W., \& Jurs, S. G. (2003). Applied statistics for the behavioral sciences. Boston: Cengage Learning, Inc.

Homack, S., \& Riccio, C. A. (2004). A meta-analysis of the sensitivity and specificity of the Stroop Color and Word Test with children. Archives of clinical Neuropsychology, 19(6), 725-743.

Hopkins, W. G. (2000). Measures of reliability in sports medicine and science. Sports medicine, 30(1), 115.

Hughes, P. K., Bhundell, N. L., \& Waken, J. M. (1993). Visual and psychomotor performance of elite, intermediate and novice table tennis competitors. Clinical and Experimental Optometry, 76 (2), 51-60.

Huijgen, B. C., Leemhuis, S., Kok, N. M., Verburgh, L., Oosterlaan, J., Elferink-Gemser, M. T., \& Visscher, C. (2015). Cognitive Functions in Elite and Sub-Elite Youth Soccer Players Aged 13 to 17 Years. PloS one, 10(12), e0144580.

Hung, T. M., Spalding, T. W., Santa Maria, D. L., \& Hatfield, B. D. (2004). Assessment of reactive motor performance with event-related brain potentials: attention processes in elite table tennis players. Journal of Sport and Exercise Psychology, 26(2), 317-337.

International Table Tennis Federation. (2018). Classification Rules for ITTF Para Table Tennis. Rules consistent with the 2015 IPC Athlete Classification Code and accompanying International Standards. Retrieved from: https://www.ipttc.org/classification/Rules/ITTFPTT\%20Classification\%20Rules\%202018.pdf

Kannekens, R., Elferink-Gemser, M. T., \& Visscher, C. (2011). Positioning and deciding: Key factors for talent development in soccer. Scandinavian Journal of Medicine \& Science in Sports, 21, 846-852. doi:10.1111/j.16000838.2010.01104.x 
Kondrič, M., Zagatto, A.M., \& Sekulić, D. (2013). The physiological demands of table tennis: a review. Journal of Sports Science and Medicine, 12, 362-370.

Lansbergen, M.M., Kenemans, J.L., \& van Engeland, H. (2007). Stroop interference and attentiondeficit/hyperactivity disorder: A review and metaanalysis. Neuropsychology, 21 (2), 251.

Lees, A. (2003). Science and the major racket sports: a review. Journal of Sports Science and Medicine, 12, 362370.

Logan, G.D. (1994). On the ability to inhibit thought and action: A users' guide to the stop signal paradigm. In: Dagenbach D, Carr TH, eds. Inhibitory processes in attention memory and language. San Diego CA: Academic Press. 189-239.

Mantis, K., Zachopoulou, E., \& Mavridis, T. (1998). A battery of tests for evaluating abilities related to the tennis serve. Journal of Human Movement Studies, 35(2), 73-87.

McLeod, T. C. V., Barr, W. B., McCrea, M., \& Guskiewicz, K. M. (2006). Psychometric and measurement properties of concussion assessment tools in youth sports. Journal of athletic training, 41 (4), 399.

Miyake, A., Friedman, N.P., Emerson, M.J., Witzki, A.H., Howerter, A. \& Wagner, T.D. (2000). The unity and diversity of executive functions and their contributions to complex "frontal lobe" tasks: A latent variable analysis. Cognitive Psychology, 41, 49-100.

Monsell, S. (1996). Control of mental processes. In V. Bruce (Ed.), Unsolved mysteries of the mind: Tutorial essays in cognition (pp. 93-148). Hove, UK: Erlbaum.

Munivrana, G., Furjan-Mandić, G., \& Kondrič, M. (2015). Determining the Structure and Evaluating the Role of Technical-Tactical Elements in Basic Table Tennis Playing Systems. International Journal of Sports Science and Coaching, 10(1), 111-132.

Nikolić, I., Furjan-Mandić, G., \& Kondrič, M. (2014). The relationship of morphology and motor abilities to specific table tennis tasks in youngsters. Collegium Antropologicum, 1, 241-245.

Panjan, A., Sarabon, N., \& Filipčič, A. (2010). Prediction of the successfulness of tennis players with machine learning methods. Kinesiology, 42 (1), 98-106.
Raab, M., Masters, R. S., \& Maxwell, J. P. (2005). Improving the 'how'and 'what'decisions of elite table tennis players. Human movement science, 24(3), 326-344.

Reitan, R.M. (1971). Trail Making Test results for normal and brain-damaged children. Perceptual and Motor Skills, 33, 575-81.

Rognoni, T., Casals-Coll, M., Sánchez-Benavides, G., Quintana, M., Manero, R. M., Calvo, L., ... \& PeñaCasanova, J. (2013). Estudios normativos españoles en población adulta joven (proyecto NEURONORMA jóvenes): normas para las pruebas Stroop Color-Word Interference Test $\mathrm{y}$ Tower of London-Drexel University. Neurología, 28(2), 73-80.

Sanchez-Cubillo, I., Perianez, J. A., Adrover-Roig, D., Rodriguez-Sanchez, J. M., Rios-Lago, M., Tirapu, J. E. E. A., \& Barcelo, F. (2009). Construct validity of the Trail Making Test: role of task-switching, working memory, inhibition/interference control, and visuomotor abilities. Journal of the International Neuropsychological Society, 15(3), 438.

Schmidt, R.A., \& Lee, T.D. (2011). Motor control and learning: A behavioral emphasis (5th ed.). Champaign IL: Human Kinetics.

Strauss, E., Sherman, E.M.S., \& Spreen, O. (2006). A compendium of neuropsychological tests: Administration, norms, and commentary. USA: Oxford University Press.

Swanson, J. (2005). The Delis-Kaplan Executive Function System: A Review. Canadian Journal of School Psychology, 20, 117-128.

Tombaugh, T. N. (2004). Trail Making Test A and B: normative data stratified by age and education. Archives of clinical neuropsychology, 19(2), 203-214.

Verburgh, L., Scherder, E. J., van Lange, P. A., \& Oosterlaan, J. (2014). Executive functioning in highly talented soccer players. PloS one, 9(3), e91254.

Vestberg, T., Gustafson, R., Maurex, L., Ingvar, M., $\&$ Petrovic, P. (2012). Executive functions predict the success of top-soccer players. PloS one, 7(4), e34731.

Walsh, V. (2014). Is sport the brain's biggest challenge? Current biology, 24(18), R859-R860.

Wang, C. H., Chang, C. C., Liang, Y. M., Shih, C. M., Chiu, W. S., Tseng, P., ... \& Juan, C. H. (2013). Open vs. closed skill sports and the modulation of inhibitory control. PloS one, 8(2), e55773. 
Wang, B., Guo, W., \& Zhou, C. (2016). Selective enhancement of attentional networks in college table tennis athletes: a preliminary investigation. PeerJ, 4, e2762. 